\title{
KESEIMBANGAN KEHIDUPAN-KERJA DAN NIAT UNTUK MENGUNDURKAN DIRI: STUDI MANAJER PERBANKAN SYARIAH DI JAWA BARAT
}

\author{
WORK-LIFE BALANCE AND INTENTION TO QUIT: STUDY OF SHARIA BANKING MANAGERS \\ IN WEST JAVA
}

\author{
Silvy Sondari Gadzali ${ }^{* 1}$ \\ *) Universitas Subang \\ Jl. R.A. Kartini KM. 3, Pasirkareumbi, Kec. Subang, Subang 41285, Indonesia
}

\begin{abstract}
Top management is important to maintain aspects of work-life balance, especially for managers with high responsibilities and work intensity. If this does not get attention, it will result in increased work stress, disharmony in family relationships, decreased work focus and increased work accidents. This study aims to examine job satisfaction and organizational commitment to mediate the relationship between worklife balance and intention to resign. To get primary data, an online survey was conducted on managers at ten private Islamic banks in West Java. The survey results found 223 respondents, with a response rate of 32 per cent. The results of quantitative calculations using SPSS show that work-life satisfaction is negatively correlated with the managers' intention to quit. The results of the mediation analysis show that work satisfaction and organizational commitment become partial mediators in the relationship between work-life balance and intention to resign. This study also discusses the implications of managers of private Islamic banks in West Java. The findings in this study are useful for understanding the implementation of work-life balance and its relationship to the intention of resigning managers.
\end{abstract}

Keywords: Work-life balance; intention to quit, sharia bank managers, work satisfaction, organizational commitment

\begin{abstract}
Abstrak: Manajemen puncak penting untuk menjaga aspek keseimbangan kehidupankerja terutama bagi para manajer dengan tanggung jawab dan intensitas pekerjaan yang tinggi. Jika hal ini tidak mendapat perhatian, akan berakibat pada peningkatan stress kerja, ketidakharmonisan hubungan keluarga, menurunnya fokus kerja dan peningkatan kecelakaan kerja. Studi ini bertujuan menguji kepuasan kerja dan komitmen organisasi memediasi hubungan antara keseimbangan kehidupan-kerja dan niat mengundurkan diri. Untuk mendapatkan data primer dilakukan survei online pada manajer di sepuluh bank syariah swasta di Jawa Barat. Hasil survei didapatkan 223 responden, dengan response rate sebesar 32 persen. Hasil penghitungan kuantitatif dengan menggunakan SPSS menunjukkan bahwa kepuasan kehidupan-kerja berkorelasi negatif dengan niat mengundurkan diri para manajer. Hasil dari analisis mediasi menunjukkan bahwa kepuasan kerja dan komitmen organisasi menjadi mediator secara parsial dalam hubungan antara keseimbangan kehidupan kerja dan niat mengundurkan diri. Studi ini membahas pula implikasi manajer bank syariah swasta di Jawa Barat. Temuan dalam studi ini bermanfaat untuk memahami implementasi kesimbangan kehidupan-kerja dan hubungannya dengan niat mengundurkan diri para manajer.
\end{abstract}

Kata kunci: keseimbangan kehidupan-kerja; niat untuk mengundurkan diri, manajer bank syariah, kepuasan kerja, komitmen organisasi

\footnotetext{
${ }^{1}$ Alamat korespondensi:

Email: silvysondari@unsub.ac.id
} 


\section{PENDAHULUAN}

Keseimbangan kehidupan kerja kini menjadi topik penelitian yang mendapat banyak perhatian. Keseimbangan kehidupan kerja telah menjadi perhatian bagi peneliti yang tertarik pada kualitas kehidupan kerja dan hubungannya dengan kualitas hidup secara lebih luas (Haar dan Russo, 2013). Keseimbangan kehidupan-kerja telah menjadi objek perdebatan pada sektor pemerintahan, akademisi, dan praktisi managerial (Seierstad dan Kirton, 2015). Diyakini bahwa dengan menyeimbangkan karier yang sukses dengan kehidupan pribadi atau keluarga adalah sesuatu yang menantang, dan dapat berpengaruh pada kepuasan seseorang terhadap peran-peran pekerjaan dan kehidupan pribadinya (Seierstad dan Kirton, 2015).

Keseimbangan kehidupan-kerja adalah tentang bagaimana seorang pekerja secara mandiri mengelola peran antara pekerjaan dan semua kegiatan yang penting bagi individu seperti keluarga, kegiatan masyarakat, pengembangan pribadi, dan rekreasi. Kemampuan untuk menyeimbangkan kebutuhan tempat kerja dan kebutuhan kehidupan pribadi dianggap sebagai isu yang penting secara global bagi para pekerja, termasuk manajer di berbagai level organisasi (Lewis dan Humbert, 2010).

Di Indonesia, khususnya di Jawa Barat kinerja perbankan syariah sepanjang tahun 2017 hingga 2019 tumbuh secara positif dan stabil yang secara dominan ditopang oleh kinerja Bank Umum Syariah. Namun share perbankan syariah masih tergolong sangat kecil, yaitu sebesar 8,36\% jika dibandingkan dengan total aset perbankan Jawa Barat pada tahun 2019 (Lukihardianti, 2020). Minimnya pemahaman tentang mekanisme transaksi keuangan syariah dan lebih lagi dipupuk dengan rasa acuh untuk berusaha memahami mekanisme syariah, pada akhirnya akan menghasilkan sebuah simpulan masyarakat bahwa ternyata praktik perbankan syariah tidak berbeda dengan konvensional. Penjelasan inilah yang sepertinya menjadi salah satu alasan utama mengapa perbankan syariah belum bisa berkembang secara optimal di Indonesia (Rahmanti, 2019). Belum lagi masalah umum seperti masih terdapatnya kendala permodalan, teknologi, karakteristik produk dan layanan yang belum dapat memenuhi kebutuhan masyarakat dan sumber daya manusia (SDM).
Peran SDM berkualitas dalam upaya manjalankan dan mengembangkan organisasi marupakan kunci asset utama. Asset berwujud yang dimiliki seperti properti, alat dan mesin fabrikasi hanya akan menjadi modal yang tidak berkontribusi optimal jika tidak didukung oleh kapabilitas SDM. Sehingga begitu pentingnya keahlian SDM adalah salah satu aspek yang diandalkan untuk meningkatkan daya saing organisasi (Plessis dan Niekerk, 2017).

Berforkus pada peningkatan kemampuan SDM yang berorientasi pada daya saing organisasi, manajer berperan secara amat strategis pada penanganan kompleksitas pekerjaan dalam lingkungan bisnis yang semakin kompetitif. Perbankan syariah adalah lembaga keuangan berbasis kaidah hukum muamalah agama islam. Di sinilah peran manajer mampu mengelola talenta SDM agar perbankan syariah dapat memenuhi kompleksitas kebutuhan transaksi nasabah yang tidak bertentangan dengan Syariah.

Namun, harus dipahami juga bahwa tuntutan yang terlalu besar yang dibebankan pada para manajer dapat berdampak pada ketidakjelasan terkait peran pribadi dan konflik kerja dan kurangnya kejelasan (lack of clarity) terkait peran menyebabkan ambiguitas peran dan konflik peran (Helfat dan Peteraf, 2015). Keduanya akan berdampak signifikan terhadap tercapainya tujuan pribadi dan organisasi, yang menyebabkan kecemasan karyawan (employee anxiety), ketidakpuasan (dissatisfaction) dan efektivitas organisasi yang rendah (Armstrong et al. 2015). Peran-peran ganda di tempat kerja yang dijalankan manajer, ditambah tekanan-tekanan organisasi dan harapan pihak lain dapat menjadi faktor pemicu yang mempengaruhi kepuasan keseimbangan kehidupan-kerja, yang akan mempengaruhi sikap kerja mereka seperti kepuasan kerja, komitmen organisasi, dan niat mengundurkan diri (Seierstad dan Kirton, 2015).

Niat mengundurkan diri telah banyak diteliti yang berkontribusi tentang temuan-temuan aspek positif dan negatif dari turnover (Ghosh et al. 2013). Turnover sebagai sebuah akibat karena masalah yang ada dan ditimbulkan oleh kesulitan yang dihadapi organisasi dalam merekrut dan mempertahankan para karyawan (Hussain et al. 2013). Penelitian ini memiliki dua tujuan. Pertama, untuk menguji hubungan antara kepuasan keseimbangan kehidupan-kerja dan Niat untuk mengundurkan diri pada manajer perbankan syariah di Jawa Barat. Kedua, untuk melihat apakah 
kepuasan kerja dan komitmen organisasi memediasi hubungan antara kepuasan keseimbangan kehidupankerja dan niat mengundurkan diri pada manajer.

Keseimbangan kehidupan-kerja memiliki runtun konsekuensi yang penting bagi sikap karyawan terhadap organisasi dan kehidupannya (Haar dan Russo, 2013). Sehingga penting untuk diteliti tren keseimbangan kehidupan-kerja dan perkembangannya yang mempengaruhi well-being dan hasil kerja para karyawan di tempat kerja. Isu-isu terkait menjaga dan mencapai keseimbangan kehidupan-kerja telah menarik perhatian yang cukup besar beberapa tahun belakangan, namun hanya sedikit yang berupaya mengungkap realita kepuasan keseimbangan kehidupan-kerja pada manajer di sector perbankan (Dajani, 2015; Grawitch et al. 2010; Mikkelson et al. 2015).

Namun sebelumnya penting memahami definisi keseimbangan kehidupan-kerja. Memahami definisi konsep keseimbangan kehidupan-kerja adalah memahami hal yang kompleks, sebagaimana konsep ini dapat dilihat dari makna 'kerja', 'kehidupan', dan 'keseimbangan' itu sendiri (Lewis dan Humbert, 2010). Keseimbangan kehidupan-kerja adalah tentang bagaimana mengelola peran antara pekerjaan dan semua kegiatan yang penting bagi kualitas kehidupan individu seperti keluarga, kegiatan masyarakat, pengembangan pribadi, dan rekreasi (Kim, 2014). Definisi selanjutnya tantang keseimbangan kehidupan-kerja digambarkan sejauh mana individu, secara seimbang, terlibat dan puas dengan peran pekerjaan dan peran keluarganya (Wambui et al. 2017). Dengan demikian, karyawan dengan tingkat keseimbangan kehidupan-kerja yang tinggi adalah mereka yang mampu mencurahkan waktu dan komitmen pada domain pekerjaan dan nonpekerjaan dalam porsi yang hampir sama (Lingard et al. 2017).

Telah banyak penelitian yang dilakukan untuk mengungkap hubungan antara Keseimbangan kehidupan-kerja dan luaran sikap kerja (attitudinal job outcome) seperti kepuasan kerja dan komitmen organisasi (Fayyazi dan Aslani, 2015; Seierstad dan Kirton, 2015; ter Hoeven et al. 2017). Sebagai contoh, penelitian pada karyawan yang terkena pemutusan hubunga kerja (PHK) di Hong Kong menemukan bahwa keseimbangan kehidupan-kerja memiliki hubungan yang positif dengan kepuasan kerja (Kim, 2014). Selanjutnya, penelitian pada 249 manajer perbankan di Swedia menyimpulkan bahwa konflik pekerjaan-keluarga merefleksikan bahwa keseimbangan kehidupan-kerja memiliki hubungan yang signifikan dengan kepuasan kerja dengan intensitas pekerjaan (Mikkelson et al. 2015).

Dalam sebuah studi tentang hubungan antara kepuasan karyawan dengan praktik SDM dan komitmen afektif terhadap organisasi ditemukan bahwa keseimbangan kehidupan-kerja memiliki hubungan dengan komitmen organisasi dari semua kelompok karyawan. Literatur yang ada terkait keseimbangan kehidupan-kerja cenderung untuk membuat beberapa asumsi, dan salah satunya adalah asumsi bahwa meningkatkan keseimbangan kehidupan-kerja manajer tingkat bawah dan menengah di perusahaan jasa keuangan, tidak hanya akan meningkatkan produktivitas namun juga loyalitas terhadap perusahaan serta menjaga turunnya intensi untuk meninggalkan organisasi (Sharma dan Pareek, 2019).

Variabel niat untuk mengundurkan diri berasosiasi positif dengan pengunduran diri yang sesungguhnya (Yukongdi, 2020). Niat individu untuk keluar dari organisasi telah dimasukkan ke dalam berbagai model attitude (Ghosh et al. 2013). Penelitian terkait anteseden dari turnover, secara tradisional, fokus pada dampak bahwa sikap kerja, seperti kepuasan kerja dan komitmen organisasi, terhadap niat untuk mengundurkan diri karyawan.

Temuan bahwa kepuasan kerja dan komitmen organisai secara parsial memediasi hubungan antara occupational stress dan niat untuk mengundurkan diri. Temuan ini sangat relevan dengan penelitian ini, mengingat bahwa kepuasan kerja dan komimen adalah variabel mediator dan niat untuk mengundurkan diri adalah variabel outcome yang akan diterliti. Namun, mayoritas penelitian ini dilakukan dalam organisasi, dimana tujuannya adalah untuk menurunkan tingkat turnover pada level perusahaan (Khalique et al. 2018; Lingard et al. 2017).

Penelitian ini melanjutkan penelitian (Gulisashvili dan Tankov, 2016) yang menemukan peningkatan produktivitas kerja sebagai akibat dari menajemen perusahaan atas keseimbangan kehidupan-kerja yang baik. Lebih lanjut, (Dajani, 2015; Fayyazi dan Aslani, 2015) menyajikan bukti empiris bahwa upaya perusahaan untuk membantu karyawan mencapai keseimbangan antara kehidupan kerja dan kehidupan di rumah berhubungan dengan komitmen dari semua kelompok karyawan. Selanjutnya penelitian (Fayyazi 
dan Aslani, 2015; Gallie et al. 2017) yang menggunakan variabel motivasi, kinerja karyawan dan OCB sebagai variabel intervensi.

Tujuan penelitian ini adalah untuk mengetahui hubungan antara keseimbangan kehidupan-kerja dan niat untuk mengundurkan diri, dengan menggunakan kepuasan kerja dan komitmen organisasi sebagai variabel interensi. Sepanjang pengetahuan peneliti belum ada penelitian yang menguji hubungan keseimbangan kehidupankerja dan niat untuk mengundurkan diri yang dimediasi oleh kepuasan kerja dan komitmen organisasi. Dan hal ini yang menjadi motivasi dilakukannya penelitian ini. Metode penyelesaian masalah pada penelitian ini mereplikasi dari penelitian yang dilakukan oleh (Khalique et al. 2018) yaitu dengan melakukan pengujian atas respon para manajer karena memiliki intensitas dan kompleksitas kehidupan kerja dan keluarga yang lebih tinggi dan dapat lebih layak untuk dijadikan sampel penelitian.

\section{METODE PENELITIAN}

Populasi dalam penelitian ini adalah para manajer menengah bank syariah di kantor operasional setingkat kantor cabang (KC) dan kantor cabang pembantu (KCP) di Jawa Barat. Data yang digunakan yang digunakan adalah data primer. Perolehan data dilakukan dengan cara melakukan interview tidak langsung yaitu menyebar kuesioner kepada sampel. Selama Januari 2019 hingga Juli 2019 berhasil direkrut 223 sampel dari 697 orang manajer, 10 bank Syariah di Jawa Barat. Responden ini mewakili 32\% dari keseluruhan populasi dari beragam tingkatan manajerial. Profil responden selanjutnya pada Tabel 1.

Tabel 1. Profil responden

\begin{tabular}{lcc}
\hline Variabel & No. & $\%$ \\
\hline Usia & & \\
$30-39$ & 91 & 41 \\
$40-49$. & 114 & 51 \\
50 dan lebih & 18 & 8 \\
Jenis Kelamin & & \\
Lelaki & 132 & 59 \\
Perempuan & 91 & 41 \\
Masa Jabatan & & \\
1-9 tahun & 42 & 19 \\
10-19 tahun & 76 & 34 \\
20 lebih tahun & 105 & 47 \\
\hline
\end{tabular}

Setiap kepala kantor cabang utama bank syariah dihubungi dan didorong untuk berpartisipasi dengan mengikutsertakan manajernya dalam studi ini melalui surat resmi untuk berpartisipasi dalam penelitian, lembar informasi partisipasi, dan link survei online untuk mendapatkan data primer. Prosedur menghubungi sampel diulang sebanyak tiga kali untuk mengingatkan terkait survei ini. Semua instrumen dipasang di sebuah program survei online. Hasil survei yang telah diisi kemudian dihitung dan disimpan, dan hasilnya dimasukkan ke dalam SPSS 22.0 untuk kebutuhan analisis kuantitatif.

Beberapa item dalam skala ini ditulis dalam bentuk kalimat negatif untuk menjaga reliabilitas jawaban dari responden. Pertanyaan dalam kalimat negatif ini dikodifikasi secara terbalik sebelum melakukan pengecekan reliabilitas. Semua instrumen, kecuali kuesioner demografi, dijawab menggunakan skala likert 6 poin yang terdiri dari 1 (sangat tidak setuju sekali), 2 (sangat tidak setuju), 3 (tidak setuju), 4 (setuju), 5 (sangat setuju), 6 (sangat setuju sekali).

Hubungan antara semua variabel dalam penelitian ini dilihat menggunakan koefisien korelasi pearson product-moment. Sesuai dengan tujuan penelitian penelitian ini menguji hubungan keseimbangan kehidupan-kerja, dengan memodifikasi instrumen keseimbangan kehidupan-kerja yang dikembangkan oleh (Lewis dan Humbert, 2010; Wambui et al. 2017). Instrumen tersebut terdiri dari 6 item. Semua item digabungkan untuk menggambarkan keseimbangan kehidupan-kerja setiap responden, nilai Cronbach's alpha instrumen instrument ini sebesar 0,81 . Variabel niat untuk mengundurkan diri diukur menggunakan tiga item yang menilai respon terkait niat untuk meninggalkan perusahaan secara keseluruhan. Nilai Cronbach's alpha instrumen ini sebesar 0,88 .

Penelitian ini menggunakan dua buah variabel mediasi yaitu kepuasan kerja dan komitmen organisasi. Kepuasan kerja menggunakan 6 item yang mengukur perasaan para manajer bank terkait kepuasan kerja mereka. Nilai Cronbach's alpha instrumen ini sebesar 0,89 . Selanjutnya, komitmen organisasi bertujuan untuk mengukur tingkat komitmen organisasi para manajer secara umum dari para responden menggunakan 18 item. Nilai Cronbach's alpha instrumen ini sebesar 0,81 . 
Berdasarkan kajian literatur yang dilakukan, hipotesis berikut ini diajukan: Studi pada eksekutif pemasaran ditemukan bahwa konflik pekerjaan-kehidupan memiliki hubungan yang negatif dan signifikan dengan turnover intention dan keseimbangan kehidupan-kerja tidak berpengaruh pada penurunan tingkat niat untuk mengundurkan diri, yang berdampak pada rendahnya tingkat turnover (Ghosh et al. 2013; Khalique et al. 2018). Berdasar pada hal tersebut diajukan hipotesis 1 yaitu terdapat hubungan negatif dan signifikan antara kepuasan keseimbangan kehidupan-kerja dan niat untuk mengundurkan diri.

Banyak penelitian yang dilakukan untuk meneliti hubungan antara keseimbangan kehidupan-kerja dan luaran sikap kerja (attitudinal job outcome) seperti kepuasan kerja dan komitmen organisasi (Fayyazi dan Aslani, 2015; Seierstad dan Kirton, 2015; ter Hoeven et al. 2017). Penelitian pada karyawan yang terkena pemutusan hubungan kerja di Hong Kong menemukan bahwa keseimbangan kehidupan-kerja memiliki hubungan yang positif dengan kepuasan kerja (Kim, 2014). Selanjutnya penelitian pada manajer perbankan di Swedia menyimpulkan bahwa konflik pekerjaan-keluarga merefleksikan bahwa keseimbangan kehidupan-kerja memiliki hubungan positif dengan kepuasan kerja dengan komitmen organisasi (Mikkelson et al. 2015). Berdasar pada hal tersebut diajukan hipotesis 2 yaitu hubungan antara kepuasan keseimbangan kehidupan-kerja dan niat untuk mengundurkan diri akan dimediasi secara penuh oleh kepuasan kerja. Dan hipotesis 3 terdapat hubungan antara kepuasan keseimbangan kehidupankerja berpengaruh secara signifikan pada komitmen organisasi.

Gambar 1 adalah kerangka konseptual yang dikembangkan berdasarkan kajian literatur terkait atas hubungan keseimbangan kehidupan-kerja dan Niat untuk mengundurkan diri pada manajer perbankan syariah di Jawa Barat, dan kepuasan keseimbangan kerja yang diintervensi oleh dua variabel yaitu kepuasan kerja dan komitmen organisasi terhadap niat untuk mengundurkan diri.

\section{HASIL}

Statistik Deskriptif untuk semua variabel yang digunakan dalam studi ini ditunjukkan pada Tabel 2, semua variabel menunjukkan variasi yang signifikan. Nilai rata-rata tiap variabel menunjukkan bahwa variabel dalam studi ini terdistribusi normal. Nilai ini didukung oleh hasil uji normalitas yang dilakukan menggunakan Kolmogorov-Smirnov, dimana semua variabel menunjukkan hasil non-signifikan (nilai signifikan lebih dari 0,05) menandakan normalitas.

\section{Hipotesis 1 = Analisis Korelasi}

Berdasarkan temuan korelasi pada Tabel 3, kepuasan keseimbangan kehidupan-kerja menunjukkan korelasi yang positif dan signifikan dengan kepuasan kerja $(r=$ $0.43, p \leq 0.01)$ dan komitmen organisasi $(r=0.36, p$ $\leq 0.01)$. Namun, kepuasan keseimbangan kehidupankerja menunjukkan hubungan yang negatif dan signifikan dengan niat untuk mengundurkan diri $(r=$ $-0.38, p \leq 0.01$ ). Sehingga, hipotesis 1 yang menyatakan bahwa kepuasan keseimbangan kehidupan-kerja memiliki hubungan negatif dengan niat untuk mengundurkan diri diterima. Variabel keseimbangan kehidupan-kerja, kepuasan kerja, komitmen organisai, dan niat untuk mengundurkan diri memiliki hubungan yang signifikan satu sama lain. Temuan ini relevan untuk memberikan temuan-temuan signifikan pada tahap analisis moderasi.

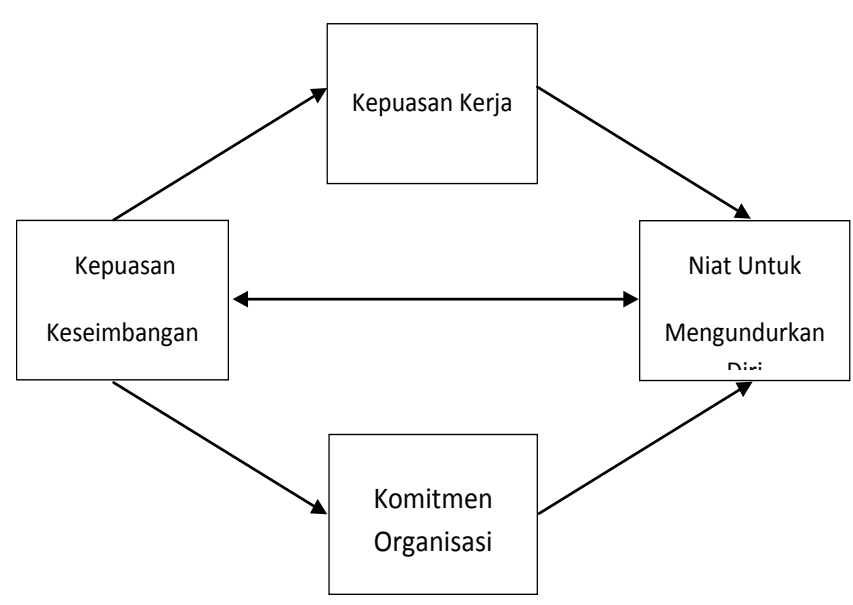

Gambar 1. Kerangka pemikiran penelitian 
Tabel 2. Latar Belakang Responden dan Statistik Deskriptif ( $\mathrm{n}=223$ )

\begin{tabular}{llllll}
\hline Variabel & Deskripsi & Min. & Max. & Rerata & SD \\
\hline Kepuasan & & & & & \\
Keseimbangan kehidupan kerja & Indeks 6 item & 6 & 30 & 3,18 & 0,65 \\
Kepuasan kerja & Indeks 6 item & 6 & 30 & 3,69 & 0,85 \\
Komitmen & & & & & \\
Organisasi & Indeks 18 item & 23 & 85 & 3,48 & 0,52 \\
Niat untuk mengundurkan diri & Indeks 3 item & 3 & 15 & 2,48 & 1,17 \\
\hline
\end{tabular}

Tabel 2: Korelasi bivariat antar semua variabel penelitian

\begin{tabular}{llll}
\hline Variabel & 1 & 2 & 3 \\
\hline 1, Keseimbangan Kehidupan-Kerja & & & \\
2, Kepuasan kerja &, $432^{* *}$ & & \\
3, Komitmen Organisasi &, $364^{* *}$ &, $635^{* *}$ & \\
4, Niat untuk mengundurkan diri &,$- 376^{* *}$ &,$- 960^{* *}$ &,$- 568^{* *}$ \\
\hline
\end{tabular}

Keterangan: ${ }^{* *} \mathrm{p}<0,01$ level (2-tailed), ${ }^{*} \mathrm{p}<0,05$ level (2-tailed),

Studi ini mendukung penelitian dan literatur yang ada bahwa kepuasan karyawan atas keseimbangan kehidupan-kerja akan meminimialisir niat mereka untuk meninggalkan perusahaan (Ghosh et al. 2017; Khalique et al. 2018; Kim, 2014; ter Hoeven et al. 2017; Wambui et al. 2017). Para manajer yang merasa puas bekerja di lingkungan kerja yang peduli dan memberi ruang untuk menyeimbangkan kebutuhan kehidupan dan kebutuhan pribadi dan di tempat kerja. Perlu dicatat pula bahwa temuan studi ini sejalan dengan penelitian yang menunjukkan bahwa keseimbangan kehidupan-kerja berkorelasi positif dengan kepuasan kerja dan komitment organisasi (Fayyazi dan Aslani, 2015; Gallie et al. 2017; Mikkelson et al. 2015; Seierstad dan Kirton, 2015). Maka dari itu, hal ini menunjukkan bahwa keseimbangan kehidupan-kerja memiliki dampak penting pada sikap karyawan dalam konteks studi ini, niat untuk mengundurkan diri dalam organisasi serta kehidupan karyawan.

Selain itu, studi ini juga mengungkap bahwa kepuasan kerja dan komitmen organisasi secara parsial memediasi hubungan antara kepuasan keseimbangan kehidupankerja dan niat untuk mengundurkan diri. Temuan mediasi membuktikan fakta yang dijelaskan bahwa kepuasan kerja dan komitmen memberikan pengaruh yang kuat pada niat untuk meninggalkan perusahaan. Perbankan syariah nampak memberikan hal-hal positif secara agamis untuk menyelaraskan kehidupan karier manajer dan harmonisasi kehidupan keluarga. Namun, hasil survei yang dilakukan baru-baru ini menemuka bahwa manajer dilaporkan bahwa mereka merasakan tingkat stress yang tinggi karena beban target pekerjaan yang terus meningkat dan tingginya rasio manajer dan bawahan, tekanan untuk menarik dana-dana eksternal dan menjaga kolektibilitas pembiayaan (Arsalan, 2014; Perdana dan Gunawan, 2017).

Analisis mediasi dilakukan menggunakan teknik yang dikembangkan oleh (Ali Memon et al. 2018; Laosirihongthong et al. 2013). Teknik mediasi ini dipilih dengan pertibangan bahwa penelitian ini fokus menyelidiki hubungan-hubungan sederhana antara tiga dimensi variabel (variabel prediktor, mediator, dan output). Studi ini juga menerapkan analisis regresi berganda yang terdiri dari empat persamaan regresi, mengacu pada langkah-langkah yang dikemukakan dalam menentukan mediasi (Ali Memon et al. 2018; Laosirihongthong et al. 2013).

Pengaruh mediasi muncul ketika empat kondisi atau langkah terpenuhi. (a) Kondisi 1 (variabel independen harus secara signifikan memprediksi variabel dependen); (b) Kondisi 2 (variabel independen harus secara signifikan memprediksi variabel mediator); (c) Kondisi 3 (variabel mediator harus secara signifikan memprediksi variabel dependen, dan predictive ulitilty dari variabel independen harus secara signifikan diturunkan ke nol, dibandingkan dengan Kondisi 1, ketika variabel independen dan mediator digunakan secara bersamaan untuk memprediksi variabel dependen); (d) Kondisi 4 (memastikan bahwa variabel mediator memediasi secara penuh hubungan antara variabel prediktor dan variabel outomce, pengaruh dari 
prediktor terhadap outcome yang mengontrol mediator harus nol. Jika kempat kondisi di atas terpenuhi, dapat dikatakan bahwa data konsisten dengan hipotesis bahwa variabel mediator memediasi hubungan antara prediktor dan outcome. Sebaliknya, jika hanya tiga kondisi pertama yang terpenuhi, dimana koefisien regresi untuk variabel independen menjadi rendah namun tetap signifikan secara statistik, maka dapat dikatakan bahwa terjadi mediasi parsial) (Ali Memon et al. 2018; Laosirihongthong et al. 2013).

Pengujian hipotesis 2, kami mengatakan bahwa hubungan antara kepuasan keseimbangan kehidupankerja dan niat untuk mengundurkan diri akan dimediasi secara penuh (fully mediated) oleh kepuasan kerja. Temuan dari analisis mediasi yang dilakukan menggunakan langkah-langkah sebagai berikut: (a) kepuasan keseimbangan kehidupan-kerja secara signifikan memprediksi niat untuk mengundurkan diri $(\beta=-0,34, p<0,05)$; (b) dilakukan analisis regresi untuk mengetahui peran kepuasan kerja sebagai variabel yang mungkin memediasi hubungan antara kepuasan keseimbangan kehidupan-kerja dan niat untuk mengundurkan diri. Diketahui bahwa kepuasan keseimbangan kehidupan-kerja secara signifikan memprediksi kepuasan kerja $(\beta=0,57, p<0,05)$; (c) koefisien regresi unstandardized untuk kepuasan keseimbangan kehidupan-kerja dan kepuasan kerja signifikan ketika digunakan secara bersama untuk memprediksi niat untuk mengundurkan diri $(\beta=0,04$, $p<0,05$ and $\beta=-0,68, p<0,05)$.

Berdasarkan analisis, tiga kondisi terpenuhi. Namun, koefisien regresi unstandardized untuk perespsi kepuasan keseimbangan kehidupan-kerja dan kepuasan kerja ketika digunakan secara bersama-sama untuk memprediksi niat untuk mengundurkan diri menungjukkan nilai yang signifikan. Menurut langkahlangkah penentuan mediasi berdasarkan, varabel kepuasan kerja memediasi secara parsial hubungan antara kepuasan keseimbangan kehidupan-kerja dan niat untuk mengundurkan diri.

Untuk menilai signifikansi pengaruh mediasi dari kepuasan kerja dalam hubungan antara kepuasan keseimbangan kehidupan-kerja dan niat untuk mengundurkan diri, penelitian ini menggunakan nilai kritis berdasarkan distribusi teoritis dari produk dua variabel acak normal $(\mathrm{P}=Z \alpha Z \beta)$ untuk menguji signifikansi hubungan mediasi antara kepuasan keseimbangan kehidupan kerja; kepuasan kerja; niat untuk mengundurkan diri (Gulisashvili dan Tankov, 2016). Hasil pengujian $Z \alpha Z \beta$ menunjukkan bahwa kepuasan kerja secara signifikan memediasi hubungan antara kepuasan keseimbangan kehidupan-kerja dan niat untuk mengundurkan diri ( $\mathrm{P}=1653,85, p<$ $0,05)$. Berdasarkan analisis causal step dan temuan uji signifikansi, komitmen organsasi secara keseluruhan secara signifikan dan secara parsial memediasi hubungan antara kepuasan keseimbangan kehidupankerja dan niat untuk mengundurkan diri. Dengan demikian, hipotesis 2 diterima secara parsial.

Sebagaimana dibuktikan oleh temuan penelitian ini, stress terhadap keseimbangan antara pekerjaan dan kehidupan pribadi pada manajer bank syariah akan mempengaruhi sikap dalam pribadi mereka seperti kepuasan kerja, komitmen, dan niat untuk mengundurkan diri, yang mana akan mengakibatkan turnover yang sesungguhnya. Tuntutan globalisasi ekonomi dan persaingan yang kian ketat telah mempengaruhi sektor perbankan terutama perbankan Syariah untuk menerapkan prinsip market-driven dalam hubungannya dengan praktik dan kebijakan tempat kerja (Çokgezen dan Kuran, 2015; Sharma dan Pareek, 2019). Bagi manajer, hal ini berarti semakin tingginya beban kerja, semakin tingginya ekspektasi terkait target dan bertambahnya tugas administratif. Selain itu, mereka harus berusaha dengan sumberdaya yang berkurang dan proses kerja yang dinamis (Kalayci dan Tekin, 2016; Perdana dan Mardiana, 2018).

Pada hipotesis 3, bahwa hubungan antara kepuasan keseimbangan kehidupan-kerja dan niat untuk mengundurkan diri akan dimediasi secara penuh oleh komitmen organisasi. Temuan dari analisis mediasi yang dilakukan menggunakan langkahlangkah sebagai berikut: (a) kepuasan keseimbangan kehidupan-kerja secara signifikan memprediksi niat untuk mengundurkan diri $(\beta=-0,34, p<0,05)$; (b) dilakukan analisis regresi untuk mengetahui peran komitmen organisasi sebagai variabel yang mungkin memediasi hubungan antara kepuasan keseimbangan kehidupan-kerja dan niat untuk mengundurkan diri. Diketahui bahwa kepuasan keseimbangan kehidupankerja secara signifikan memprediksi kepuasan kerja ( $\beta$ $=0,88, \mathrm{p}<0,05$ ); (c) koefisien regresi tidak baku untuk kepuasan keseimbangan kehidupan-kerja dan komitmen organisasi signifikan ketika digunakan secara bersama untuk memprediksi niat untuk mengundurkan diri $(\beta=$ $-0,18, p<0,05$ and $\beta=-0,19, p<0,05)$. Berdasarkan analisis, tiga kondisi terpenuhi. 
Namun, koefisien regresi unstandardized untuk perespsi kepuasan keseimbangan kehidupan-kerja dan komitmen organisasi ketika digunakan secara bersamasama untuk memprediksi niat untuk mengundurkan diri menunjukkan nilai yang signifikan. Menurut langkahlangkah menentukan mediasi varabel komitmen organisasi memediasi secara parsial hubungan antara kepuasan keseimbangan kehidupan-kerja dan niat untuk mengundurkan diri. Hasil pengujian $Z \alpha Z \beta$ menunjukkan bahwa komitmen organisasi secara signifikan memediasi hubungan antara kepuasan keseimbangan kehidupan-kerja dan niat untuk mengundurkan diri $(\mathrm{P}=$ $-242,36, p<0,05)$. Berdasarkan analisis causal step dan temuan uji signifikansi, komitmen organisasi secara signifikan dan secara parsial memediasi hubungan antara kepuasan keseimbangan kehidupan-kerja dan niat untuk mengundurkan diri. Maka hipotesis 3 diterima secara parsial.

Manajer dituntut untuk menunjukkan komitmen yang lebih daripada karyaan bawahannya. Jabatan manajer membutuhkan komitmen yang lebih tinggi sehingga secara tidak langsung manajer dipaksa untuk memberi perhatian lebih pada pekerjaannya, dan hanya memiliki sedikit waktu untuk kehidupan dan keluarganya. Penting untuk memikirkan bahwa pada tingkat organisasi, ada beberapa tindakan yang dapat diterapkan oleh manajemen untuk meningkatkan dan menjaga praktik dan kebijakan keseimbangan kehidupan-kerja dan meminimalisir tingkat turnover pada level manajer. Sebagai contoh, fleksibilitas kerja di tempat kerja menjadi bagian tak terpisahkan dari pekerjaan, khususnya bagi perusahaan yang berada di jasa, yang akan sangat terpengaruh pada isu terkait keseimbangan hehidupan-kerja (Arsalan, 2014). Selain itu diungkapkan pula bahwa strategi untuk membantu menyeimbangkan pekerjaan dan kehidupan adalah memberikan jam kerja yang fleksibel seperti saat manajer dapat menikmati waktu libur dengan semestinya dan saat cuti; Memberikan pengaturan kerja yang fleksibel seperti job sharing dan sesekali dapat melakukan bekerja dari rumah; Memberikan peluang pelatihan saat bekerja; Menyediakan fasilitas dan bawahan yang cukup bagi manajer sehingga mereka dapat menyelesaikan tugasnya dengan baik; Memberikan waktu istirahat cukup saat hari kerja; Membuat ketentuan untuk berbagai jenis izin tidak masuk; Memberi penghargaan pada manajer atas pencapaian atas pekerjaannya, bukan hanya sekadar kehadirannya; Jika memungkinkan, menyediakan peluang kesehatan dan well-being seperti akses atau waktu olahraga; dan Mendorong praktik manajemen yang jelas.

Sebagai contoh, penelitian tentang perbedaan tentang nilai keseimbangan kehidupan-kerja antara pria dan wanita, antara manajer senior dan junior, dan dampaknya pada niat untuk mengundurkan diri. Penelitian selanjutnya terkait keseimbangan kehidupankerja dan niat untuk mengundurkan diri, diharapkan bahwa akan ada intervensi yang lebih baik yang dapat diterapkan bank untuk menciptakan dan menjaga tingkat keseimbangan kehidupan-kerja yang optimal dan fokus pada kelompok manajer, serta meminimalisir niat mereka meninggalkan organisasi.

\section{Implikasi manajerial}

Implikasi manajerial dari kepuasan keseimbangan kehidupan-kerja telah menjadi isu penting bagi perusahaan secara umum, dan semakin penting di sektor perbankan. Selanjutnya, penelitian ini menggabungkan variabel attitude yang berpotensi memediasi hubungan, yaitu kepuasan kerja dan komitmen organisasi. Dari sudut pandang keseimbangan kehidupan-kerja dan niat untuk mengundurkan diri pada manajer di perbankan Syariah Jawa Barat, studi ini berhasil menemukan beberapa aitem penting. Temuan studi ini adalah bahwa keseimbangan kehidupan-kerja berkorelasi negatif dengan niat untuk mengundurkan diri pada manajer bank Syariah di Jawa Barat.

\section{KESIMPULAN DAN SARAN}

\section{Kesimpulan}

Ukuran perusahaan bank syariah tidak sebesar bank konvensional. Dengan demikian, organisasi kantor operasional $\mathrm{KC}$ dan $\mathrm{KCP}$ pun belum besar dengan jumlah transaksi yang tidak terlalu banyak. Namun tingkat kehati-hatian atas banyaknya aturan perbankan yang membuat manajer harus tetap fokus. Untuk itu manajemen bank syariah telah melakukan beberapa hal yang mendukung keseimbangan kehidupan-kerja yaitu, (1) praktik manajemen yang berbasis kejujuran dan tanggung jawab atas amanah (2) manajemen memberikan fasilitas kerja di kantor yang sangat memadai, (3) memberikan penghargaan secara rutin di berbagai level karyawan berprestasi, (4) karyawan yang berprestasi diprioritaskan untuk dapat mengikuti pelatihan dan pengembangan. Perlu digarisbawahi 
bahwa hasil penelitian ini didasarkan pada manajer dari bank syariah yang berpartisipasi, sehingga tidak mungkin untuk melakukan generalisasi pada manajer di bank lainnya di Jawa Barat. Penelitian sejenis juga perlu dilakukan pada area perbankan konvensional yang lebih luas dengan pemisahan dan fokus pada manajer bank swasta dan milik pemerintah.

\section{Saran}

Melalui hasil studi ini, perlu dilakukan penelitian lebih lanjut terkait kondisi keseimbangan kehidupan-kerja para manajer bank syariah, serta hubungannya dengan sikap dan perilaku penting lainnya. Penelitian tersebut bisa meliputi stress kerja, organizational citizenship behavior, dan dukungan perusahaan serta abseteeism, variabel-variabel ini berdasarkan perbedaan jenis kelamin, usia, masa jabatan, dan variabel demografi pribadi lainnya.

\section{DAFTAR PUSTAKA}

Ali $\mathrm{M}$ et al. 2018. Mediation Aanalysis issues and recommendations. Journal of Applied Structural Equation Modeling 2(1): 2590-4221.

Armstrong G, Atkin-Plunk CA, Wells J. 2015. The relationship between work-family conflict, correctional officer job stress, and job satisfaction. Criminal Justice and Behavior 42(10): 1-17. https://doi.org/10.1177/0093854815582221

Arsalan M. 2014. Organizational cynicism and employee turnover intention: evidence from banking sector in Pakistan. Pakistan Journal of Commerce and Social Sciences 8(1): 30-41.

Çokgezen M, Kuran T. 2015. Between consumer demand and Islamic law: The evolution of Islamic credit cards in Turkey. Journal of Comparative Economics 43(4): 862-882. https:// doi.org/10.1016/j.jce.2015.07.005

Dajani MAZ. 2015. The impact of employee engagement on job performance and organisational commitment in the egyptian banking sector. Journal of Business and Management Science 3(5): 138-147. https://doi.org/10.12691/jbms-3$5-1$

Fayyazi M, Aslani F. 2015. The impact of worklife balance on employees' job satisfaction and turnover intention; the moderating role of continuance commitment. International Letters of Social and Humanistic Sciences 51(im): 33-
41. https://doi.org/10.18052/www.scipress.com/ ilshs.51.33.

Gallie D et al. 2017. The implications of direct participation for organisational commitment, job satisfaction and affective psychological well-being: a longitudinal analysis. Industrial Relations Journal 48(2): 174-191. https://doi. org/10.1111/irj.12174.

Ghosh P, Satyawadi R, Joshi JP, Shadman M. 2013. Who stays with you? Factors predicting employees' intention to stay. International Journal of Organizational Analysis 21(3): 288-312. https:// doi.org/10.1108/IJOA-Sep-2011-0511.

Ghosh P et al. 2017. Who stays with you? Factors predicting employees' intention to stay. International Journal of Organizational Analysis 15(3): 288-312. https://doi.org/10.21776/ ub.jam.2017.015.03.18.

Grawitch MJ, Barber LK, Justice L. 2010. Rethinking the work-life interface : it 's not about balance, it's about resource allocation. Applied Psychology: Health And Well-Being 2(2): 127-159. https:// doi.org/10.1111/j.1758-0854.2009.01023.x.

Gulisashvili A, Tankov P. 2016. Tail behavior of sums and differences of log-normal random variables. Bernoulli 22(1): 444-493. https://doi. org/10.3150/14-BEJ665.

Haar JM, Russo M. 2013. Outcomes of work-life balance of job satisfaction, life satisfaction and mental health: a study across seven cultures. Journal of Vocational Behavior 85(3): 361-373.

Helfat CE, Peteraf MA. 2015. Managerial cognitive capabilities and the microfoundations of dynamic capabilities. Strategic Management Journal. https://doi.org/10.1002/smj.2247.

Hussain IA, Yunus N, Ishak NA, Daud N. 2013. The influence of intention to leave towards employee engagement among young bankers in Malaysia. International Journal of Business and Management 8(14). https://doi.org/10.5539/ ijbm.v8n14p89.

Kalayci S, Tekin BE. 2016. Interactions between Economic Growth, FDI and Islamic Banking Development in Turkey. International Journal of Business and Management 11(8): 230. https:// doi.org/10.5539/ijbm.v11n8p230.

Khalique M, Arif I, Siddiqui M, Kazmi SW. 2018. Impact of workplace bullying on job performance, intention to leave, OCB and stress. Pakistan Journal of Psychological Research 33(1): 55-74. 
Kim HK. 2014. Work-life balance and employees' performance: the mediating role of affective commitment. Global Business and Management Research: An International Journal 6(1): 37-51. Laosirihongthong T, Adebanjo D, Choon TK. 2013. Mediationanalysis in partial least squares path modeling: helping researchers discuss more sophisticated models. Industrial Management dan Data Systems 113(8): 1008-1109. https:// doi.org/10.1108/02635570710734262.

Lewis S, Humbert AL. 2010. Discourse or reality? "Work-life balance", flexible working policies and the gendered organisation. Equality, Diversity and Inclusion: An International Journal 29(3):239-254

Lingard $\mathrm{H}$ et al. 2017. Improving employees' worklife balance in the construction industry: Project alliance case study. Journal of Construction Engineering and Management 133(10): 807815.https://doi.org/10.1061/(ASCE)07339364(2007)133:10(807).

Lukihardianti A. 2020. Emil targetkan market share perbankan syariah di Jabar. Republika.Co.Id. https://republika.co.id/berita/q56340430/ emil-targetkan-emmarket-share-emperbankansyariah-di-jabar.

MikkelsonAC,YorkJA,ArritolaJ.2015.Communication competence, leadership behaviors, and employee outcomes in supervisor-employee relationships. Business and Professional Communication Quarterly 78(3): 336-354. https://doi. org/10.1177/2329490615588542.

Perdana K, Gunawan J. 2017. Proposed integrated measurement standard to measure sustainability performance: evidence from Indonesia. In Dimensional Corporate Governance: An Inclusive Approach (pp. 251-267). Springer Nature. https://doi.org/10.1007/978-3-31956182-0.
Perdana K, Mardiana N. 2018. How managers perceive internal corporate social responsibility: an empirical study of indonesian women's employment. Redefining Corporate Social Responsibility (Vol. 13). Emerald Insight. https:// doi.org/10.1108/S2043-052320180000013013.

Plessis T, Niekerk A. 2017. Factors influencing managers' attitudes towards performance appraisal. SA Journal of Human Resources Managemet 15: 1-10.

Rahmanti VN. 2019. Mengapa perbankan syariah masih disamakan dengan perbankan konvensional? IMANENSI: Jurnal Ekonomi, Manajemen Dan Akuntansi Islam 1(1): 62-74. https://doi. org/10.34202/imanensi.1.1.2013.62-74.

Seierstad C, Kirton G. 2015. Having it all ? women in high commitment careers and work - life balance in norway. Gender, Work and Organization 22(4): 390-404. https://doi.org/10.1111/gwao.12099.

Sharma D, Pareek S. 2019. Organisational commitment, job embeddedness and turnover intention: a comparative study on bank employees. Journal of the Gujarat Research Society 21(16):430-440.

ter Hoeven CL et al. 2017. The work must go on: the role of employee and managerial communication in the use of work-life policies. Management Communication Quarterly 31(2): 194-229. https://doi.org/10.1177/0893318916684980.

Wambui ML, Cherotich BC, Emily T, Dave B. 2017. Effects of work life balance on employees' performance in institutions of higher learning. a case study of Kabarak University. Kabarak Journal of Research dan Innovation 4(2): 60-79.

Yukongdi V. 2020. The influence of affective commitment, job satisfaction and job stress on turnover intention: a study of Nepalese bank employees. Review of Integrative Business and Economics Research 9(1): 88-99. 